\title{
MOTIVAÇÕES E MODOS DE FORMAÇÃO DE ESTRATÉGIAS AMBIENTAIS NO SETOR SUCROALCOOLEIRO BRASILEIRO
}

\author{
Shirley Luanna Vieira Peixoto Genuíno \\ Mestre em Administração pela Universidade Federal da Paraíba \\ shirleyluanna@hotmail.com \\ André Gustavo Carvalho Machado \\ Doutor em Administração pela Universidade Federal de Pernambuco \\ Professor Adjunto da Universidade Federal da Paraíba \\ agcmachado@gmail.com
}

\begin{abstract}
RESUMO
Este artigo tem como objetivo identificar fatores motivadores e modos de formação de estratégias ambientais adotados por empresas pertencentes ao setor sucroalcooleiro brasileiro. Para isto, foi realizada uma pesquisa cross-sectional, com caráter descritivo, e aplicado um survey por telefone. A população da pesquisa foi formada por 364 empresas, das quais 102 compuseram a amostra. Foram utilizados, procedimentos estatísticos descritivos e univariados nas análises. Os resultaram demonstraram que o atendimento à legislação, a busca pela minimização dos impactos ambientais e valorização da imagem são os principais fatores que têm motivado os gestores para realização de investimentos em prol do meio ambiente. Evidenciou-se que o planejamento foi o modo mais adotado $(75,5 \%)$ para formulação de estratégias ambientais, seguido do processual $(64,74 \%)$ e guarda-chuva $(55,9 \%)$, todavia, elas não são mutuamente excludentes, tampouco estas formas estão distribuídas igualmente entre as regiões do país.
\end{abstract}

Palavras-chave: Formação de estratégias; Gestão ambiental; Setor sucroalcooleiro brasileiro; Survey.

\section{MOTIVATIONS AND MODES OF FORMATION OF ENVIRONMENTAL STRATEGIES FOR THE BRAZILIAN SUGAR-ETHANOL SECTOR}

\begin{abstract}
This article aims to identify motivating factors and modes of formation of environmental strategies adopted by sugar-ethanol companies in the Brazilian sector. For this, a cross-sectional research study was implemented, with descriptive characteristics and an applied phone survey. The research population was comprised of 364 companies, and our sample consisted of 102 of these companies. For data analysis, we used descriptive and univariate statistical procedures. The results showed that environmental legislation, attempts to minimize environmental impacts, and maintenance of company image are the main factors that motivate managers to make investments in favor of the environment. As for the process of strategy formulation, the results showed that the conception of planned environmental strategies were the most adopted among the companies $(75.5 \%)$, followed by procedural $(64.74 \%)$ and umbrella $(55.9 \%)$ strategies. However, the strategies are not mutually exclusive and were not distributed equally among the regions of the country.
\end{abstract}

Key words: Environmental management; Formation of strategies; Sugar/ Ethanol Brazilian sector; Survey. 


\section{INTRODUÇÃO}

A Organização das Nações Unidas (ONU) anunciou, em 2011, que a população mundial chegou a sete bilhões de habitantes, um resultado três vezes maior do que foi registrado em 1950 (ONU, 2012). Tal fato demonstra que um maior número de pessoas provoca crescimento na demanda por produção de bens e serviços, e se a produção não for orientada para a minimização dos impactos ambientais, maior será a degradação do ecossistema, tendo em vista que o planeta possui limitações para suportar os rejeitos da produção industrial (Hardin, 1968).

Diante da percepção da importância desse tema, a sociedade começou a cobrar novas atitudes em relação às práticas de produção realizadas pelas organizações, com pressões sociais mais enfáticas em setores onde o impacto causado possui maior divulgação midiática (Maimon, 1994; Alperstedt et al., 2010). Os setores primário e secundário são os que mais se evidenciam quanto à exploração ambiental. No entanto, por se tratar de exploração direta de matéria-prima, o setor primário, também representado pelo agronegócio, deve possuir maior preocupação, pois é da natureza que provém seus insumos.

No Brasil, o agronegócio está em destaque. O governo federal, entre os anos de 2002 e 2010, quadruplicou a alocação de recursos no setor. Os investimentos vão desde crédito para o agricultor até a melhoria da infraestrutura que o atende (Brasil, 2012). No que tange às exportações, entre 2000 e 2011, houve um aumento de 155\%. Os principais produtos responsáveis para este crescimento foram: soja, açúcar, etanol e carnes (Fao, 2012).

Neste contexto, no agronegócio nacional, destaca-se o setor sucroalcooleiro. O Brasil é o maior produtor de açúcar e se situa no segundo lugar na produção de etanol em níveis mundiais (Unica, 2014). Todavia, o crescimento do setor expôs as organizações a uma maior cobrança no que diz respeito a um comportamento sustentável para auferir ganhos competitivos. Para isto, faz-se necessário que ocorra a incorporação de metas e ações associadas à gestão do meio ambiente às estratégias de negócio das empresas do setor. Afinal, as estratégias, quando aliadas à dimensão ambiental, podem gerar vantagem competitiva, pois há uma maior eficiência na utilização de matéria-prima, minimização de possíveis custos relacionados a penalizações quanto à legislação ambiental vigente, e agregação de valor à imagem organizacional junto aos stakeholders (Maimon, 1994).

Todavia, estudo empreendido em oito empresas pertencentes ao setor sucroalcooleiro dos estados de Pernambuco e Paraíba evidenciou que "[...] a dimensão ambiental parece estar relegada a planos funcionais específicos, sendo ainda incipiente o alinhamento entre questões operacionais e estratégicas" (Machado e Silva, p.420, 2010). Nesta perspectiva, o objetivo deste artigo é identificar fatores motivadores e modos de formação de estratégias ambientais adotados por empresas pertencentes ao setor sucroalcooleiro brasileiro.

\section{FUNDAMENTAÇÃO TEÓRICA}

Nesta seção, será apresentada, brevemente, uma revisão da literatura relacionada ao setor sucroalcooleiro brasileiro, bem como abordagens associadas aos modos de formação de estratégias, em ambos os casos, sob a perspectiva do meio ambiente.

\subsection{O setor sucroalcooleiro e o meio ambiente}

O desenvolvimento de práticas de gestão que minimizem os danos ambientais é fundamental para que as organizações continuem a realizar suas atividades com uma maior eficiência no uso dos recursos, reduzindo custos associados a potenciais multas e taxas pela infração às legislações ambientais (Barbieri, 1995). Além da otimização do uso dos recursos, o conceito de organização ambientalmente correta é percebido como um diferencial competitivo e um agregador de valor no momento da compra (Motta e Oliveira, 2007; Pickett-Baker e Ozaki, 2008; Borin, Cerf e Krishnan, 2011). 
Em consonância com estes achados, resultados de pesquisas no setor sucroalcooleiro evidenciaram que os principais fatores que têm motivado o empreendimento de ações em prol do meio ambiente são: imagem da empresa, isomorfismo mimético, regulamentação ambiental, oportunidades econômicas, e contribuição para melhoria da qualidade de vida da sociedade (Machado e Silva, 2010). Nesse mesmo estudo, concluiu-se que a preocupação ambiental se dá de diferentes formas entre as empresas analisadas. Aquelas voltadas para a exportação ou venda para multinacionais têm se esforçado para melhorar o processo produtivo industrial e a qualidade dos produtos, enquanto as empresas voltadas para o atendimento à demanda interna parecem dar mais atenção à produção de cana-de-açúcar.

Alguns aspectos e impactos negativos decorrentes das atividades desenvolvidas pelo setor sucroalcooleiro sobre o meio ambiente são: uso de agrotóxicos; contaminação do solo e da água com o uso excessivo de fertilizantes; redução da biodiversidade local em detrimento das áreas de plantio; compactação do solo pelo tráfego de máquinas durante a safra e colheita; assoreamento de corpos d'água, em decorrência da erosão do solo em períodos de renovação da lavoura; emissão de fuligens e gases de efeito estufa durante a queima; odor gerado na fase de fermentação e destilação do caldo da cana; geração da vinhaça e da torta de filtro; utilização excessiva de água no processo produtivo. (Araújo, 2001; Piacente, 2005)

Contudo, diversos problemas ambientais citados anteriormente já podem ser solucionados de forma ecologicamente correta e financeiramente rentável. A vinhaça, um subproduto da produção do álcool que possui elevado poder poluente, cerca de 100 vezes maior que um esgoto doméstico, pode ser utilizada como biofertilizante, o mesmo ocorrendo com a torta de filtro, que é a sobra da cana existente no filtro utilizado na produção (Araújo, 2001). A substituição dos fertilizantes industriais por este biofertilizante pode render uma economia de até US\$ 60,00 por hectare (Udop, 2010). Outro subproduto da produção da cana-de-açúcar é o bagaço, que pode ser utilizado para a produção de celulase (enzima que ajuda na quebra da celulose) e como proteína para ração animal (Pelizer, Pontieri e Moraes, 2007) ou, ainda, como fonte de energia (Escobar, 2012).

Pode-se, pois, compreender como certas práticas ambientais devem fazer parte do cotidiano das organizações sucroalcooleiras, tendo em vista a minimização dos impactos sobre o meio ambiente, o cumprimento da legislação e os melhores rendimentos econômicos com a utilização adequada dos resíduos. Para estimular a gestão ambiental em todas as áreas da organização, entende-se que haja a necessidade de inclusão dessa dimensão na estratégia empresarial. Este assunto será tratado na próxima seção.

\subsection{Modos de formação de estratégia e o meio ambiente}

O desenvolvimento da vantagem competitiva não advém, somente, da exploração de determinados recursos, mas sim da sua produtiva utilização (Porter e Linder, 1995). Os mesmos autores relatam que para que ocorra o bom uso dos recursos se faz necessário o debate sobre política ambiental e sua ligação com a competitividade. Egri e Pinfield (1999) classificam essa visão como ambientalismo renovado. Para eles, essa nova perspectiva insere os conceitos de economia ecológica e ecologia industrial. A primeira, é definida pela contrapartida econômica da gestão ambiental. A segunda, é caracterizada pela busca por sistemas de produção rentáveis.

Para que a organização esteja inserida nesta nova visão de competitividade, se faz necessário que a dimensão ambiental esteja presente nas decisões estratégicas da empresa, pois a disseminação de novas práticas para toda a organização ocorre quando a cúpula administrativa está envolvida e procura efetivar os conceitos (Hunt e Auster, 1990; Rohrich e Cunha, 2004). Neste sentido, os objetivos estratégicos devem estar voltados para o aumento da competitividade de uma maneira ecologicamente correta, com vistas à otimização dos recursos e a um melhor desempenho em relação aos concorrentes. Esta afirmativa é corroborada por Greeno e Robinson (1992) ao argumentarem sobre a crescente inclusão de questões associadas ao meio ambiente, saúde e segurança nos níveis estratégicos empresariais.

Revista de Gestão Social e Ambiental - RGSA, São Paulo, v. 8, n. 2, p. 76-93, maio./ago., 2014. 
Empresas que inserem questões associadas ao meio ambiente no processo de desenvolvimento de suas estratégias têm potencial de obter retornos financeiros superiores (Clarkson et al; 2011) e se tornam mais competitivas (Sharma e Vredemberg, 1998). O comportamento ambientalmente correto é promissor, seja por meio de melhorias no desempenho organizacional (Aragón-Correa; Sharma, 2003) seja devido à utilização do marketing verde, principalmente no sentido do mostrar os benefícios do consumo consciente (Juwaheer, Pudaruth e Noyaux, 2012).

Pode-se entender essa estratégia de diferentes formas (Mintzberg, Ahlstrand e Lampel, 2000). Logo, é compreensível que o modo de concebê-la não seja homogêneo e simples (Van de Ven, 1992). Mintzberg (1973), pois compreende três tipos de processos para a formação de estratégias: empreendedor, adaptativo, e planejador. Na forma empreendedora, a tomada de decisão está centrada em uma única pessoa que busca novas oportunidades continuamente. A maneira adaptativa ocorre em ambientes complexos e de difícil controle, sem a centralização do poder. As principais características da forma adaptativa são: inexistência de objetivos claros, solução reativa em relação aos problemas, as decisões são incrementais e fragmentadas. Por fim, a forma planejada consiste na presença de sistematização de análises, de maneira formal, em um ambiente razoavelmente previsível.

Outra abordagem é desenvolvida a partir dos termos: lógico, incrementalismo, e incrementalismo lógico. O primeiro, é caracterizado pelo planejamento formal, em que as análises do ambiente externo e interno são executadas, a fim de verificar pontos fortes, fracos, ameaças e oportunidades. $\mathrm{O}$ incrementalismo possui uma abordagem comportamental, fator negligenciado pelo modo lógico, e fornece informações sobre o poder psicológico e as relações informais. Por último, tem-se a junção das duas abordagens por meio do incrementalismo lógico. Este é caracterizado por ter flexibilidade na execução das atividades planejadas, procurando ser uma maneira de equilibrar as estratégias deliberadas e emergentes (Quinn, 1978). Mintzberg e Waters (1985), por sua vez, classificaram oito maneiras de conceber estratégias. Estas podem ser visualizadas na Figura 1 a seguir.

\begin{tabular}{|l|l|}
\hline Planejado & $\begin{array}{l}\text { Características } \\
\text { Previsível. Estratégia deliberada }\end{array}$ \\
\hline Empreendedor & $\begin{array}{l}\text { Apenas um indivíduo está com o controle da decisão. Comum em organizações guiadas pelos } \\
\text { seus donos. A estratégia pode ser deliberada ou emergente }\end{array}$ \\
\hline Ideológico & $\begin{array}{l}\text { Os membros da organização compartilham as mesmas intenções empresariais, ou seja, eles } \\
\text { desenvolvem uma ideologia a ser seguida. Normalmente, as ideias são originadas da história } \\
\text { organizacional. Estratégia prioritariamente deliberada. }\end{array}$ \\
\hline Guarda - chuva & $\begin{array}{l}\text { Uma estratégia ampla e central é desenvolvida pela alta administração, e decisões específicas } \\
\text { para o alcance dos objetivos macros são definidas nos diversos setores da organização. É } \\
\text { classificada como deliberadamente emergente. }\end{array}$ \\
\hline Processual & $\begin{array}{l}\text { Os líderes controlam a formulação da estratégia, mas o conteúdo destas é desenvolvido por } \\
\text { outros atores. Parcialmente deliberada e emergente. }\end{array}$ \\
\hline Não conectado & $\begin{array}{l}\text { As unidades não estão em sintonia com as matrizes. As estratégias de negócios não estão } \\
\text { alinhadas com as estratégias corporativas. Observando a organização geral, este tipo de } \\
\text { estratégia sempre será emergente. No entanto, as unidades podem desenvolver planos de ação } \\
\text { deliberados. }\end{array}$ \\
\hline Consenso & $\begin{array}{l}\text { Os agentes entram em acordo quanto ao plano de ação da estratégia. Não há controle da alta } \\
\text { administração. Ocorre a partir de ações individuais. Equipes autodirecionadas. Estratégias com } \\
\text { foco no processo emergente. }\end{array}$ \\
\hline Imposto & $\begin{array}{l}\text { O ambiente rege os padrões de ações independentemente do controle da alta administração. } \\
\text { Maior número de estratégias emergentes. }\end{array}$ \\
\hline
\end{tabular}

Figura 1: Modos de formação de estratégias

Fonte: Adaptado de Mintzberg e Waters (1985)

Revista de Gestão Social e Ambiental - RGSA, São Paulo, v. 8, n. 2, p. 76-93, maio/ago., 2014. 
A proposta destes últimos autores contempla, portanto, uma percepção mais deliberada (Planejada) até um processo mais emergente (Imposta) de criar estratégias. No entanto, é importante salientar que não há estratégias puramente emergentes ou puramente deliberadas, elas sempre contemplam diferentes intensidades em um continuum. Afinal, processos adaptativos, incrementais, de aprendizagem, culturais, visionários, entre outros, podem ser incorporados pelas empresas na busca pelo alcance de seus objetivos. Como Santos, Alves e Almeida (2007, p. 71) chamam a atenção: "mais do que 'simplesmente' navegar recorrendo sempre aos mapas e às representações 'racionais' que fazemos do mar/território, para nos dizer onde estamos e para onde vamos, é preciso 'sentir' o caminho, ajustando a nossa rota".

\section{PROCEDIMENTOS METODOLÓGICOS}

Esta pesquisa está orientada no paradigma funcionalista, apresenta um caráter positivista (Burrell e Morgan, 1979), possui uma abordagem quantitativa e se configura como descritiva (Sampieri, Collado e Lúcio, 1991). O método adotado foi o survey do tipo cross-sectional, ou seja, uma exposição da realidade em um determinado momento (Babbie, 2003). Os dados foram coletados por meio de um questionário em um único momento no tempo e, posteriormente, tratados estatisticamente (Hair, Anderson, Tatham e Black, 2009).

A população da pesquisa foi composta por todas as empresas pertencentes ao setor sucroalcooleiro nacional. O Ministério da Agricultura, Pecuária e Abastecimento divulgou, em 2011, como pertencentes ao setor, o número de 364 empresas. Procurou-se entrar em contado com todas elas, pois o objetivo inicial era a realização de um censo. No entanto, em detrimento de acessibilidade ao respondente, a amostra de pesquisa foi de 102 empresas, isto é, obteve-se 28,02\% de taxa de retorno.

O questionário foi composto por 25 questões que utilizaram, na maioria dos itens, uma escala ordinal, ou seja, houve o estabelecimento hierárquico das variáveis nos termos 'maior que' e 'menor que' (Hair et al., 2009). Para o desenvolvimento desse questionário, foram adotados quatro passos iniciais, sugeridos por Costa (2011), que são: definição dos construtos; geração de itens e validação de face e conteúdo; decisão sobre as respostas; e construção do instrumento. Neste sentido, dois construtos foram adotados: Motivadores dos Investimentos Ambientais (composto por seis afirmativas) e Modos de Formação de Estratégias (composto por 12 afirmativas), conforme figura 2. Além disto, inicialmente, sete questões foram formuladas para melhor compreender o perfil da amostra pesquisada.

\begin{tabular}{|c|c|c|}
\hline Construto & $\begin{array}{l}\text { Itens do questionário (Escala de concordância de cinco } \\
\text { pontos) }\end{array}$ & Referências \\
\hline $\begin{array}{l}\text { Motivadores } \\
\text { dos } \\
\text { investimentos } \\
\text { ambientais }\end{array}$ & $\begin{array}{l}\text { 1. Melhorar a imagem junto à sociedade é um fator que tem } \\
\text { motivado a empresa a investir em prol do meio ambiente } \\
\text { 2. Reduzir os impactos negativos causados ao ambiente pela } \\
\text { empresa é um fator que tem motivado a empresa a investir em } \\
\text { prol do meio ambiente } \\
\text { 3. Tornar-se mais competitiva no mercado é um fator que tem } \\
\text { motivado a empresa a investir em prol do meio ambiente } \\
\text { 4. A redução de custos é fator que tem motivado a empresa a } \\
\text { investir em prol do meio ambiente } \\
\text { 5. Ter acesso a financiamentos é um fator que tem motivado a } \\
\text { empresa a investir em prol do meio ambiente } \\
\text { 6. Atender à Legislação Ambiental é um fator que tem } \\
\text { motivado a empresa a investir em prol do meio ambiente }\end{array}$ & $\begin{array}{l}\text { Maimon, 1994; Porter e Linder, } \\
\text { 1995; Piacente, 2005; Barbieri, } \\
\text { 1995; Sharma e Vredemberg, } \\
\text { 1998; Alston e Roberts, 1999; } \\
\text { Sanches, 2000; Aragón-Correa e } \\
\text { Sharma, 2003; Donaire, 2006; } \\
\text { Barbieri, 2007; Machado e Silva, } \\
\text { 2010; Valentine, 2010; Clarkson } \\
\text { et al, 2011; Borin, Cerf e } \\
\text { Krishnan, 2011; Martins, 2011. }\end{array}$ \\
\hline $\begin{array}{l}\text { Modos de } \\
\text { formação de } \\
\text { estratégias }\end{array}$ & $\begin{array}{l}\text { 1. A pessoa responsável pela Gestão ambiental participa } \\
\text { corriqueiramente de reuniões para decisões estratégicas } \\
\text { 2. A gestão ambiental faz parte dos objetivos organizacionais } \\
\text { 3. Os setores da organização possuem metas específicas, } \\
\text { determinadas pela direção, quanto à gestão ambiental } \\
\text { 4. A direção propõe limites e diretrizes ambientais gerais a }\end{array}$ & $\begin{array}{l}\text { Mintzberg e Waters, 1985; } \\
\text { Idenburg, 1993; Mintzberg, } \\
\text { Alhstrand e Lampel, } 2000\end{array}$ \\
\hline
\end{tabular}

Revista de Gestão Social e Ambiental - RGSA, São Paulo, v. 8, n. 2, p. 76-93, maio./ago., 2014. 
serem seguidas por todos da organização, deixando as decisões específicas para os setores da empresa.

5. As estratégias voltadas para o meio ambiente são impostas por ocorrências, variáveis ou eventos externos à organização.

6. As principais ações estratégicas ambientais da empresa são realizadas sem planejamento prévio

7. As decisões estratégicas ambientais são decorrentes da visão e dos interesses de um único líder.

8. Há planos formais estabelecendo as estratégias ambientais da empresa

9. O desenvolvimento do planejamento estratégico ocorre com a participação dos representantes dos setores

10. A direção controla os meios (procedimentos, pessoal envolvido) de como serão elaboradas as estratégias voltadas para o meio ambiente e deixa a formulação do conteúdo destas estratégias para o pessoal alocado nos diferentes setores da organização.

11. As estratégias voltadas para o meio ambiente são elaboradas pelos setores sem, necessariamente, estarem alinhadas com as diretrizes impostas pela direção da organização.

12. As estratégias voltadas para o meio ambiente são elaboradas por meio de tentativas e erros.

Figura 2: Itens dos construtos presentes no questionário

Fonte: Elaboração própria

A validação de conteúdo ocorreu com a observação se os construtos estão sendo medidos adequadamente. Haynes, Richard e Kubany (1995) entendem validade de conteúdo como a relevância do instrumento para representar o construto analisado. Para isto, o instrumento de coleta foi enviado para um especialista, expert no desenvolvimento de escalas, que analisou sua construção e as formas de mensuração propostas. A validação de face, por sua vez, consiste na análise da clareza e representatividade das questões (Costa, 2011). Para seu alcance, foi realizado um pré-teste do instrumento de coleta de dados numa usina produtora de açúcar que não fez parte da amostra da pesquisa. Em decorrência destas tarefas, certas questões do instrumento de coleta de dados necessitaram ser revisadas.

$\mathrm{O}$ procedimento relativo à confiabilidade da escala desenvolvido foi $\mathrm{o}$ teste de confiabilidade alpha de Cronbach. A escala do construto 01 (Motivadores dos Investimentos Ambientais) obteve o resultado 0,658, e o construto 02 (Modos de Formulação de Estratégias) 0,602. Estes valores classificam o instrumento como confiável, estando, pois, apto a medir adequadamente os construtos propostos.

As unidades de análise foram as usinas de cana-de-açúcar brasileiras. A operacionalização da coleta ocorreu com a contratação de uma profissional especializada que foi responsável, junto com a sua equipe, pela aplicação, via telefone, do questionário. Os sujeitos da pesquisa foram, preferencialmente, os responsáveis pela produção ou responsáveis administrativos da organização. A escolha destes ocorreu devido a esses possuírem cargos empresariais que exercem atividade cotidiana diretamente ligada aos objetivos de pesquisa deste artigo.

Após a coleta de dados, foi utilizado, para execução dos procedimentos estatísticos, o software Statistical Package for the Social Sciences (SPSS), Pacote Estatístico para Ciências Sociais, versão 18. Procedimentos estatísticos de análises descritivas foram desenvolvidos e incluíram as medidas de posição e de variabilidade. Ainda na análise descritiva, a síntese de dados foi realizada por meio do uso de tabelas, com a apresentação dos percentuais e a distribuição de frequências. Um Teste Qui-Quadrado foi adotado para avaliar a relação entre a presença do gestor ambiental e os investimentos em gestão ambiental. 


\section{APRESENTAÇÃO E DISCUSSÃO DOS RESULTADOS}

Esta seção foi dividida da seguinte forma: inicialmente, serão apresentadas algumas características relevantes a respeito do perfil da amostra analisada, seguido pelos principais fatores que têm motivado as empresas do setor sucroalcooleiro a investirem na gestão ambiental. Por fim, foram descritos os modos de formação de estratégias ambientais.

\subsection{Perfil da amostra}

A amostra é composta por 102 empresas, que caracterizam $28,02 \%$ do universo de usinas que compõem o setor sucroalcooleiro. Destas, 21 estão localizadas no Nordeste, 1 no Norte, 12 no Centro-Oeste, 9 no Sul e 59 no Sudeste. A última região concentra o maior número de usinas no Brasil, ou seja, 210 das 364 empresas ativas. Quatro Estados brasileiros (Amapá, Roraima, Rondônia e Santa Catarina) não possuem registros com a presença de empresas do setor.

A maioria das empresas da amostra é caracterizada como média-grande ou grande empresa, segundo a classificação adotada pelo Banco Nacional de Desenvolvimento Econômico e Social (Bndes). Apenas uma usina está situada no nível de microempresa. Isto pode ser resultado da crescente importância do setor na economia nacional ou representar a necessidade de altos investimentos em infraestrutura para que haja exploração da cana-de-açúcar, o que, normalmente, é feito por grupos que já iniciam as atividades com grandes quantidades de produção. Os resultados de cada classificação podem ser observados na Tabela 01 a seguir.

Tabela 1: Faturamento anual

\begin{tabular}{l|c|c|c|c}
\multicolumn{1}{c}{ Variáveis } & \multicolumn{1}{c}{ Porte } & $\begin{array}{c}\text { Frequência } \\
\text { Absoluta }\end{array}$ & $\begin{array}{c}\text { Frequência } \\
\text { Relativa }\end{array}$ & $\begin{array}{c}\text { Percentual } \\
\text { Válido }\end{array}$ \\
Menor ou igual a R\$ 2,4 milhões & Microempresa & 1 & $1 \%$ & $7 \%$ \\
\hline $\begin{array}{l}\text { Maior que R\$ 2,4 milhões e menor ou } \\
\text { igual a R\$ 16 milhões }\end{array}$ & Pequena empresa & 7 & $6,8 \%$ & \\
\hline $\begin{array}{l}\text { Maior que R \$16 milhões e menor ou igual } \\
\text { a R\$ 90 milhões }\end{array}$ & Média empresa & 27 & $26,5 \%$ & $27 \%$ \\
\hline $\begin{array}{l}\text { Maior que R\$ 90 milhões e menor ou } \\
\text { igual a R\$ 300 milhões }\end{array}$ & $\begin{array}{c}\text { Média-grande } \\
\text { empresa }\end{array}$ & 37 & $36,2 \%$ & $36 \%$ \\
\hline Maior que R\$ 300 milhões & Grande empresa & 30 & $29,4 \%$ & $29 \%$ \\
\hline Total & & 102 & $100 \%$ & \\
\hline
\end{tabular}

Fonte: Dados da pesquisa (2012)

Com base na análise descritiva dos resultados (Tabela 2), observa-se que, para empresas de grande porte, quanto maior o faturamento maior foi o investimento em gestão ambiental $(50 \%$ dos respondentes). Para empresas de médio e médio-grande porte, essa relação entre faturamento e investimento ambiental não foi confirmada, pois, de acordo com os resultados encontrados, a faixa de investimentos para usinas deste porte é de $0,31 \%$ e $0,6 \%$ do faturamento, com 40,54\% e 40,74\% de respostas, respectivamente. Em organizações caracterizadas como microempresa e pequena empresa pôde-se observar que a maioria das empresas apresenta investimentos em gestão ambiental na faixa de $0,1 \%$ a $0,3 \%$ do faturamento.

A relação entre porte e investimento na gestão ambiental foi investigada apenas por meio do cruzamento entre as frequências de ambas as variáveis, visto que os dados coletados não atenderam aos pressupostos destacados por Levin (1987) para a realização de testes de qui-quadrado, especificamente devido à existência de muitas células com frequências menores do que cinco. 
Tabela 2: Porte e investimento na gestão ambiental.

\begin{tabular}{|c|c|c|}
\hline \multicolumn{3}{|c|}{ Faturamento anual menor ou igual a $\mathrm{R} \$ 2,4$ milhões } \\
\hline Investimento na gestão ambiental & Frequência & Frequência Relativa \\
\hline Entre $0,1 \%$ e $0,3 \%$ do faturamento & 1 & $100 \%$ \\
\hline \multicolumn{3}{|c|}{ Faturamento anual maior que R\$2,4 milhões e menor ou igual a R\$ 16 milhões } \\
\hline Investimento na gestão ambiental & Frequência & Frequência Relativa \\
\hline Entre $0,1 \%$ e $0,3 \%$ do faturamento & 4 & $57,14 \%$ \\
\hline Entre $0,31 \%$ e $0,6 \%$ do faturamento & 2 & $28,57 \%$ \\
\hline Entre $0,61 \%$ e $0,9 \%$ do faturamento & 1 & $14,28 \%$ \\
\hline \multicolumn{3}{|c|}{ Faturamento anual maior que R\$16 milhões e menor ou igual a R\$ 90 milhões } \\
\hline Investimento na gestão ambiental & Frequência & Frequência Relativa \\
\hline Entre $0,1 \%$ e $0,3 \%$ do faturamento & 8 & $29,62 \%$ \\
\hline Entre $0,31 \%$ e $0,6 \%$ do faturamento & 11 & $40,74 \%$ \\
\hline Entre $0,61 \%$ e $0,9 \%$ do faturamento & 2 & $7,40 \%$ \\
\hline Entre $0,91 \%$ e $1,2 \%$ do faturamento & 2 & $7,40 \%$ \\
\hline Acima de $1,2 \%$ do faturamento & 4 & $14,81 \%$ \\
\hline \multicolumn{3}{|c|}{ Faturamento anual maior que R\$ 90 milhões e menor ou igual a R\$ 300 milhões } \\
\hline Investimento na gestão ambiental & Frequência & Frequência Relativa \\
\hline Entre $0,1 \%$ e $0,3 \%$ do faturamento & 11 & $29,72 \%$ \\
\hline Entre $0,31 \%$ e $0,6 \%$ do faturamento & 15 & $40,54 \%$ \\
\hline Entre $0,61 \%$ e $0,9 \%$ do faturamento & 4 & $10,81 \%$ \\
\hline Entre $0,91 \%$ e $1,2 \%$ do faturamento & 3 & $8,11 \%$ \\
\hline Acima de $1,2 \%$ do faturamento & 4 & $10,81 \%$ \\
\hline \multicolumn{3}{|c|}{ Faturamento anual maior que $\mathrm{R} \$ 300$ milhões } \\
\hline Investimento na gestão ambiental & Frequência & Frequência Relativa \\
\hline Entre $0,1 \%$ e $0,3 \%$ do faturamento & 5 & $16,66 \%$ \\
\hline Entre $0,31 \%$ e $0,6 \%$ do faturamento & 7 & $23,33 \%$ \\
\hline Entre $0,61 \%$ e $0,9 \%$ do faturamento & 2 & $6,66 \%$ \\
\hline Entre $0,91 \%$ e $1,2 \%$ do faturamento & 1 & $3,33 \%$ \\
\hline Acima de $1,2 \%$ do faturamento & 15 & $50,0 \%$ \\
\hline
\end{tabular}

Fonte: Dados da pesquisa (2012)

Das empresas pesquisadas, 52,94\% possuem cargos específicos para o desenvolvimento das atividades relacionadas à gestão ambiental. Proporcionalmente ao número de empresas por região, com exceção do Norte, pois apenas uma empresa participou da pesquisa, a região Sul possui o maior número de empresas com a presença de um gestor ambiental. A média de tempo de trabalho do Gestor Ambiental na organização é de 5 anos e 5 meses. De acordo com as evidências coletadas, as pessoas que trabalham no Nordeste ocupam o cargo há cerca de 5 anos e 4 meses; no Norte há 4 anos; no Centro-Oeste, 2 anos; no Sul, 7 anos e no Sudeste, 5 anos e 10 meses.

Quanto ao gênero, 73,3\% dos cargos relacionados ao meio ambiental são ocupados por homens e $26,7 \%$, por mulheres. Nordeste e Sudeste possuem, proporcionalmente, o maior número de mulheres responsáveis pela gestão ambiental.

Observando as características da presença de um responsável pela gestão ambiental, verifica-se que foi realizada uma análise descritiva entre as respostas apresentadas nas variáveis "presença de um gestor ambiental" e "investimentos em gestão ambiental". A Tabela 3, a seguir, sintetiza os resultados obtidos na observação. Além disso, também foi possível realizar um teste qui-quadrado (Tabela 5) para avaliar a relação entre as duas variáveis supracitadas. Neste último caso, as relações mostraram-se significantes para $90 \%$ de confiança. 
Tabela 3 - Relação entre a presença do gestor e os investimentos em gestão ambiental

\begin{tabular}{l|c|c|c|c}
\multicolumn{1}{|c|}{ Investimento em gestão ambiental } & $\begin{array}{c}\text { Presença do gestor ambiental } \\
\text { Absoluta }\end{array}$ & $\begin{array}{c}\text { Frequência } \\
\text { Relativa }\end{array}$ & $\begin{array}{c}\text { Fusência do gestor ambiental } \\
\text { Absoluta }\end{array}$ & $\begin{array}{c}\text { Frequência } \\
\text { Relativa }\end{array}$ \\
\hline Entre 0,1\% e 0,3\% do faturamento & 0 & $0 \%$ & 1 & $2,08 \%$ \\
\hline Entre 0,31\% e 0,6\% do faturamento & 3 & $5,55 \%$ & 6 & $12,5 \%$ \\
\hline Entre 0,61\% e 0,9\% do faturamento & 12 & $22,22 \%$ & 16 & $33,33 \%$ \\
\hline Entre 0,91\% e 1,2\% do faturamento & 18 & $33,33 \%$ & 17 & $35,41 \%$ \\
\hline Acima de 1,2 \% do faturamento & 21 & $38,88 \%$ & 8 & $16,6 \%$ \\
\hline Total & 54 & $100 \%$ & 48 & $100 \%$ \\
\hline
\end{tabular}

Fonte: Dados da pesquisa (2012)

Tabela 4 - Teste Qui-Quadrado Chi-Square Tests

\begin{tabular}{|l|r|r|r|}
\hline & \multicolumn{1}{|c|}{ Value } & Df & $\begin{array}{c}\text { Asymp. Sig. (2- } \\
\text { sided) }\end{array}$ \\
\hline Pearson Chi-Square & $8,103^{\mathrm{a}}$ & 4 &, $088^{\star}$ \\
Likelihood Ratio & 8,695 & 4 &, 069 \\
N of Valid Cases & 102 & & \\
\hline
\end{tabular}

* Nível de significância de $10 \%$

Fonte: Dados da pesquisa (2012)

Analisando-se os resultados, pode-se verificar que os menores índices de investimento são encontrados em empresas que não possuem gestor ambiental. Dessa forma, pode-se perceber que, em empresas que possuem tal cargo, há uma maior preocupação com as práticas ambientais, tendo em vista que existe uma pessoa responsável pelo planejamento e acompanhamento das ações ambientais. A presença de um gestor ambiental proporciona um elo entre as operações cotidianas e a alta administração, realiza a coordenação das atividades que possam gerar impactos nocivos, além de, possivelmente, contribuir na elaboração de estratégias organizacionais sob uma perspectiva ambiental. Isto pode levar a menores índices de multas e taxas relacionadas a infrações legais ao meio ambiente, bem como a uma relação mais amistosa com a população circunvizinha que possa vir a sofrer com os impactos causados pelas práticas produtivas características da produção do açúcar e do álcool.

Com base nos dados apontados, podem-se identificar as seguintes características gerais das empresas participantes da pesquisa. O Apêndice A apresenta, em detalhes, as frequências das variáveis utilizadas para delimitação do perfil da amostra.

a) As empresas de médio-grande porte são predominantes no mercado;

b) As empresas de grande porte possuem os maiores investimentos em gestão ambiental em relação ao faturamento anual;

c) Mais da metade das empresas possui um gestor responsável pelo meio ambiente;

d) Atualmente, o tempo de ocupação no cargo de gestão ambiental é de 5 anos e 5 meses;

e) O cargo é ocupado predominante pelo gênero masculino;

f) Nas empresas com a presença de um gestor ambiental, os valores investidos pela organização no meio ambiente são maiores.

g) O maior número de gestores ambientais, proporcionalmente à quantidade de empresas por região, encontra-se no Sul do país.

\subsection{Fatores motivadores para o investimento em gestão ambiental}

Os achados permitiram evidenciar que, em 95,01\% das organizações analisadas, a regulamentação ambiental é um fator motivador para a realização de investimentos em prol do meio ambiente. Este entendimento está em consonância com Barbieri (1995) e Maimon (1994), que 
chamaram a atenção para o fato de que o não cumprimento dos requisitos legais incorre em penalizações, por meio de multas e taxas, que corroem a competitividade da empresa.

Por sua vez, 93,13\% dos respondentes entendem que reduzir os impactos negativos causados pelas atividades organizacionais no meio ambiente é um fator motivador para a realização de investimentos. Além de atuar preventivamente para eliminar as causas das ocorrências, este comportamento também está relacionado com a inserção de práticas ambientais nos processos utilizados pela empresa (Donaire, 2006). De acordo com Barbieri (2007), a redução dos impactos negativos pode ser considerada como primordial para o desenvolvimento da gestão ambiental, pois é a partir das ações que buscam minimizar esses impactos que surgem práticas voltadas para o uso consciente dos recursos naturais.

Com o propósito de melhorar sua imagem no mercado, 87,3\% das empresas pesquisadas empreendem investimentos em prol do meio ambiente. Este resultado corrobora os achados de Sanches (2000), Alston e Roberts (1999) e Borin, Cerf e Krishnan (2011), os quais chamam a atenção para o fato de que uma gestão voltada para o meio ambiente agrega valor aos produtos sob a ótica da sociedade, diferenciando a empresa em relação aos seus rivais.

A favor do aumento da competitividade empresarial, 83,3\% dos sujeitos da pesquisa entendem que seja importante a realização dos investimentos ambientais. Este resultado vai ao encontro dos achados de Clarkson et al (2011), os quais chamaram a atenção para o fato de que empresas que optam por melhorar o seu desempenho ambiental têm um melhor desempenho econômico, maior fluxo de caixa, gastam mais com $P \& D$ e têm um maior crescimento em relação às empresas que permanecem no grupo de baixo desempenho ambiental. Sharma e Vrendenburg (1998, p. 750), por sua vez, destacaram que "[...]foram encontradas evidências do desenvolvimento de uma capacidade de integração dos stakeholders, maior disposição para aprendizagem, e uma capacidade de inovação contínua em empresas rotuladas como proativas em estratégias ambientais".

Para 70,3\% dos respondentes, reduzir custos, por meio de investimentos na gestão ambiental, é um fator motivador. No entanto, $29,7 \%$ das empresas pesquisadas possuem uma visão baseada no controle, isto é, entendem os dispêndios ambientais apenas como geradores de custos. Estas últimas parecem não perceber que investir em práticas ambientais que conduzam à diminuição ou eliminação de resíduos decorrentes do processo produtivo pode acarretar na elevação dos índices de produtividade, pois se melhora a eficiência na transformação de matéria-prima e insumos em produtos, na medida em que os recursos produtivos são mais bem aproveitados.

Verificou-se que $65,4 \%$ das empresas pesquisadas concordam que ter acesso ao financiamento é um fator influenciador para a realização de investimentos ambientais. A este respeito, Piacente (2005, p. 77), ao discorrer sobre empresas ambientalmente corretas e possuidoras de Sistemas de Gestão Ambiental, destaca que "[...] desfrutar de uma boa imagem, baixo risco de problemas de multas, indenizações, passivos ambientais e interdições por acidente ambientais fazem com que essas empresas tenham uma maior facilidade na obtenção de financiamentos".

Isto fica evidente quando se constata que instituições financeiras têm condicionado a concessão de empréstimos financeiros a critérios de risco socioambiental, tais como apregoados nos Princípios do Equador. Os principais bancos internacionais incluem os Princípios do Equador em seu processo de análise para financiamentos de quantias acima de US\$ 10 milhões. No Brasil, têmse como participantes: Bradesco, Banco do Brasil, Itaú Unibanco e Caixa Econômica Federal. (Equator Principles, 2012). Além disso, Valentine (2010) relata que os stakeholders, ambientalistas ou não, preferem não ter o capital associado a uma empresa que possui alto risco ambiental.

A fim de verificar se os resultados encontrados eram diferentes estatisticamente nas regiões do país, foram realizados, a um nível de significância de 0,01 , os seguintes testes: comparação entre médias com $\sigma^{1}$ e $\sigma^{2}$ conhecidos e Anova para dados normais e Mann-Whitney e Kruskal-Wallis para não normais. Para a operacionalização dos testes, as regiões do país foram consideradas populações. Após a análise dos testes, não foram verificadas diferenças estatísticas entre o resultado nacional e as regiões do país. A tabela 4, a seguir, sintetiza os resultados encontrados:

Revista de Gestão Social e Ambiental - RGSA, São Paulo, v. 8, n. 2, p. 76-93, maio/ago., 2014. 
Tabela 4: Fatores motivadores

\begin{tabular}{c|l|c}
\multicolumn{1}{c}{ Fanking } & \multicolumn{1}{c}{ Percentual de concordância } \\
\hline $\mathbf{1}^{\mathbf{0}}$ & Legislação & $95,01 \%$ \\
\hline $\mathbf{2}^{\mathbf{o}}$ & Minimização dos impactos ambientais nocivos & $93,13 \%$ \\
\hline $\mathbf{3}^{\mathbf{0}}$ & Melhoria da imagem & $87,3 \%$ \\
\hline $\mathbf{4}^{\mathbf{0}}$ & Aumento da competitividade & $83,3 \%$ \\
\hline $\mathbf{5}^{\mathbf{0}}$ & Redução de custos & $70,3 \%$ \\
\hline $\mathbf{6}^{\mathbf{0}}$ & Acesso a financiamentos & $65,4 \%$ \\
\hline
\end{tabular}

Fonte: Dados da pesquisa (2012)

Assim, como se pode perceber, o cumprimento da legislação é a variável mais importante na percepção dos respondentes da pesquisa, seguido da busca da minimização dos impactos causados. Em terceiro lugar, tem-se a melhoria da imagem organizacional. Em quarto, a procura por aumento de competitividade. Em quinto, tem-se a busca pela redução de custos, e, por fim, em sexto, variável acesso a financiamentos.

\subsection{Modos de formação de estratégias ambientais}

A identificação dos modos de formação de estratégias ambientais foi realizada à luz da classificação proposta por Minzberg e Waters (1985). Considerando que as formas de criação de estratégias podem ter um cunho mais deliberado ou mais emergente, entende-se que os modos de formação de estratégias façam parte de um continuum. Neste sentido, para identificar os modos adotados pelas empresas pertencentes à amostra, houve a necessidade de investigar tanto ações intencionais (por exemplo, a existência de planos formais cujos objetivos e metas ambientais estão inseridos), quanto ações que foram executadas sem uma intenção prévia (por exemplo, reações a ocorrências ambientais).

Os resultados permitiram constatar que uma mesma empresa pode adotar mais do que um modo para formação da estratégia. Esta evidência vai ao encontro dos achados da pesquisa empreendida por Vasconcelos (2001, p. 13), que concluiu que executivos adotam pressupostos de diferentes escolas (e não uma em particular) sobre o processo de formação de estratégia e “ [...] isso não deve ser tomado como um sinal de irracionalidade da prática, e sim como um lembrete que a prática está repleta de contingências e que as teorias são frequentemente simplificadoras demais para dar conta de todas as complexidades, econômicas, técnicas e humanas da estratégia empresarial".

A forma de concepção planejada foi a mais adotada pelas empresas da amostra e é caracterizada pela presença de planos formais na organização. Nela, a empresa busca sistematizar as ações, documentá-las e declará-las para conhecimento das partes envolvidas. Mintzberg e Waters (1985) relatam que empresas que priorizam esse tipo de estratégia possuem um ambiente razoavelmente previsível. Entre as empresas pesquisadas, $75,5 \%$ das organizações possuem planos formais que estabelecem a gestão ambiental. Entre estas, $87,01 \%$ têm representantes departamentais no processo de elaboração do planejamento ambiental. Ademais, 66,7\% das organizações possuem em seus setores metas determinadas pela direção sobre o desempenho desejado quanto à gestão ambiental. A Tabela 5, a seguir, apresenta a distribuição de empresas, em suas respectivas regiões, que adotam estes comportamentos.

Tabela 5: Formulação de estratégias planejadas nas regiões do país.

\begin{tabular}{l|l|l|l|l|l|l} 
& \multicolumn{2}{l}{ Nordeste } & Norte & \multicolumn{1}{l}{ Centro-Oeste } & \multicolumn{1}{l}{ Sul } \\
Presença de planos formais estabelecendo as & $56,00 \%$ & $100 \%$ & $66,66 \%$ & $100 \%$ & $76,27 \%$ \\
estratégias ambientais da empresa. & $f=14$ & $f=1$ & $f=8$ & $f=9$ & $f=45$ \\
\hline Participação dos gestores departamentais no & $92,85 \%$ & $100 \%$ & $87,5 \%$ & $77,77 \%$ & $86,66 \%$ \\
planejamento estratégico ambiental* & $f=13$ & $f=1$ & $f=7$ & $f=7$ & $f=39$ \\
\hline Os setores da organização possuem metas específicas, & $52,00 \%$ & $100 \%$ & $66,66 \%$ & $88,88 \%$ & $62,71 \%$ \\
determinadas pela direção, quanto à gestão ambiental. & $f=13$ & $f=1$ & $f=8$ & $f=8$ & $f=37$ \\
\hline
\end{tabular}

*Percentual em relação às presenças que possuem planos formais de gestão ambiental.

Fonte: Dados da pesquisa (2012) 
Observando-se a Tabela 5, pode ser verificado que o Nordeste é a região que possui o menor índice de empresas com planos formais sobre a gestão ambiental. Porém, as empresas que realizam tal prática na região, 92,85\%, possibilitam a participação dos gestores departamentais no processo de formulação do planejamento estratégico. No Sul, pode ser observado que todas as empresas respondentes da pesquisa realizam planos formais para o estabelecimento de estratégias ambientais, e em $88,88 \%$ delas há metas específicas para os setores.

Corroborando a adoção de um modo planejado de elaborar estratégias, 87,30\% das empresas participantes confirmaram a inserção da gestão ambiental nos objetivos organizacionais. No entanto, não se pode pressupor que, por estas empresas possuírem a gestão ambiental nos seus objetivos formais, elas venham a praticar a gestão ambiental. Corroborando este pensamento, Marinho (1990, p. 22) faz a seguinte afirmativa "[...] mesmo quando os objetivos são identificados com certa precisão, não se pode afirmar que a estrutura esteja automaticamente dada. Objetivos e estrutura organizacionais devem ser vistos como resultados da construção social da realidade". Assim, pode-se compreender que objetivos são formalizações para um possível alcance, o que nem sempre refletem a situação atual da empresa.

Com uma visão diferente, Sanches (2000, p. 78) relata que quando as organizações começam a autorregulação em relação à gestão ambiental, inicia-se um processo de inserção desta dimensão nas metas e políticas da empresa. Dessa forma, a “[...]proteção ambiental passa a fazer parte de seus objetivos de negócios e o meio ambiente não é mais encarado como um adicional de custo, mas como uma possibilidade de lucros, em um quadro de ameaças e oportunidades para a empresa". Nesta perspectiva, os objetivos ocorrem após a mudança de realidade, diferente do defendido por Marinho (1990) que relata que objetivos formais e realidade podem ser distintos entre si.

O percentual de empresas cuja gestão ambiental está inserida nos objetivos está distribuído nas regiões da seguinte forma: $100 \%$ das organizações do Nordeste e Norte, $83,33 \%$ no CentroOeste, 77,77 no Sul e $84,74 \%$ no Sudeste. Entre as organizações que possuem a gestão ambiental nos objetivos organizacionais, 51,68\% têm em seu quadro de funcionários o cargo de gestor ambiental. Esse resultado faz com que seja percebido que a presença ou ausência de tal cargo não parece interferir na inserção da gestão ambiental nos objetivos formais da empresa.

Verificou-se que 55,9\% das empresas respondentes adotam o modo Guarda-Chuva de formação de estratégia. Moriotto (2003) relata que este tipo estabelece estruturas flexíveis e encoraja culturas de apoio ao objetivo da cúpula administrativa. Nele há objetivos gerais propostos pelas organizações, mas é nos setores que se definem quais ações serão realizadas e como elas vão ocorrer. Entre as empresas que adotam este modo, 22,80\% estão no Nordeste; $1,75 \%$, no Norte; $14,03 \%$, no Centro-Oeste; 7,01\%, no Sul e 54,38\%, no Sudeste.

Constatou-se também que $16,66 \%$ das empresas respondentes adotam o modo não conectado de formação de estratégia para o meio ambiente. Sua principal característica é que estratégias dos departamentos/filiais não estão alinhadas aos objetivos da administração geral/matriz. O percentual encontrado está dividido nas regiões da seguinte forma: $17,64 \%$ no Nordeste; $0 \%$ no Norte; $11,76 \%$ no Centro-Oeste; $11,76 \%$ no Sul e 58,82 no Sudeste. A frequência mais baixa de ocorrência deste modo de formação de estratégia pode ser explicada devido ao grau nocivo que comportamentos como estes, normalmente, ocasionam nas organizações. De acordo com Schermerhorn, Hunt e Osborn (1998), quando os setores não estão alinhados aos objetivos centrais da empresa há um grande número de estratégias não planejadas e, em casos mais graves, pode ser iniciado um processo de contra cultura.

Entre as empresas participantes, $19,60 \%$ adotam o modo empreendedor de formular estratégias ambientais. Este resultado se distribui da seguinte forma entre as regiões do país: $25,00 \%$ no Nordeste; $0 \%$ no Norte; $15,00 \%$ no Centro-Oeste; $0 \%$ no Sul e $60,00 \%$ no Sudeste. Mintzberg et al (2000, p. 103) relatam que os líderes das empresas com formulação do tipo Empreendedora possuem, normalmente, determinadas características como "[...]forte necessidade de controle, de independência e realização, ressentimento em relação à autoridade e a tendência a

Revista de Gestão Social e Ambiental - RGSA, São Paulo, v. 8, n. 2, p. 76-93, maio/ago., 2014. 
aceitar riscos moderados". Com base nestes resultados e características, pode-se presumir que em organizações com este tipo de estratégia haja uma alta centralização de poder.

Verificou-se que $62,74 \%$ das empresas respondentes afirmaram adotar um modo processual para elaborar suas estratégias ambientais. Esta maneira é caracterizada pelo foco no método de formulação, ou seja, os líderes estão preocupados com a forma com que as estratégias serão desenvolvidas e não, exclusivamente, em seu conteúdo (Mintzberg e Waters, 1985). Este tipo de formulação dá oportunidade para os líderes trabalharem os procedimentos e utilizarem modelos específicos para o desenvolvimento de estratégias. O percentual de aderentes a este modo foi assim distribuído entre as regiões do país: $18,75 \%$ no Nordeste; $1,56 \%$ no Norte; $10,93 \%$ no CentroOeste; $9,37 \%$ no Sul e 59,37\% no Sudeste.

Entre as empresas participantes da pesquisa, 46,07\% indicaram que concebem suas estratégias ambientais sob o modo imposto, isto é, o ambiente externo rege os padrões de ação das organizações, ou seja, as decisões estratégicas são reativas, com forte característica emergente. Barney e Hesterly (2007) definem seis elementos interrelacionados que compõem o ambiente geral enfrentado pelas organizações, são eles: mudanças tecnológicas, tendências demográficas tendências culturais, clima econômico, condições legais e políticas e acontecimentos internacionais específicos. As empresas que adotam este modo estão distribuídas da seguinte forma entre as regiões do país: $23,40 \%$ estão no Nordeste; $2,12 \%$ no Norte; $8,51 \%$ no Centro-Oeste; $10,63 \%$ no Sul e 55,31\% no Sudeste.

Para uma melhor visualização de como se deu a distribuição dos percentuais dos modos de formação de estratégias, um ranking com os resultados foi desenvolvido (Tabela 6).

Tabela 6 - Modos de formação de estratégias

\begin{tabular}{l|l} 
Estratégia & Percentual de concordância \\
Planejada & $75,50 \%$ \\
\hline Processual & $64,74 \%$ \\
\hline Guarda-chuva & $55,90 \%$ \\
\hline Imposta & $46,07 \%$ \\
\hline Empreendedora & $19,60 \%$ \\
\hline Não conectada & $16,66 \%$
\end{tabular}

Fonte: Dados da pesquisa (2012)

De acordo com os resultados apresentados, pode-se caracterizar o setor sucroalcooleiro com o uso, predominantemente, do modo de planejamento para formação de estratégia. Em segundo lugar, esta a estratégia com foco no método de elaboração das ações, denominada Processual. Nela os líderes procuram controlar a forma de desenvolver as estratégias e não o conteúdo destas. Em seguida, há as estratégias do tipo Guarda-chuva, que apresentam flexibilização das ações, desde que elas estejam alinhadas com a direção. Em quarto, é observado o tipo Imposto. Nesta última, verifica-se a importância do ambiente externo, pois é ele que norteia as principais ações da alta administração. Um dos fatores que procuram explicar o alto índice da estratégia do tipo Imposta são as características do setor, pois ele é, frequentemente, atingido por alterações legais, do ambiente natural e pelas oscilações econômicas. Por fim, $16,66 \%$ declaram a presença de estratégias do tipo não conectadas.

\section{CONSIDERAÇÕES FINAIS}

As evidências permitem concluir que a maioria das usinas que compõe o setor sucroalcooleiro é de médio-grande, vindo na sequência, as grandes, médias, pequenas e microempresas. Quanto aos valores investidos no meio ambiente, foi verificado que as empresas de grande porte realizam maiores investimentos. Um dos motivos que podem explicar este resultado é o nível de cobrança social que essas empresas são expostas. Organizações maiores são alvos de uma maior observação por parte da sociedade, pois os impactos de suas ações, normalmente, afetam um grande número de pessoas. O cargo de gestor ambiental é ocupado por cerca de metade das 
organizações pesquisadas, e nele há predominância do sexo masculino. Nas empresas que possuem tal cargo há maiores investimentos em gestão ambiental.

Entre os fatores que mais têm motivado as empresas a investirem no meio ambiente, atender à legislação obteve o maior índice de concordância, seguido da redução dos impactos negativos no meio ambiente e melhoria da imagem da empresa. Estes resultados podem ser decorrentes de custos associados ao não cumprimento legal, maior conscientização social sobre a necessidade de explorar os recursos naturais de maneira sustentável e à nova realidade mercadológica que impõe a preocupação ambiental como um fator diferenciador na comercialização de produtos e serviços.

Sobre o modo de formação das estratégias, os dados apontaram para uma tendência maior para o uso do modo "planejado" para o estabelecimento de estratégias ambientais. Essas empresas buscam planejar e formalizar suas intenções, bem como deixar claro o que querem e como desejam alcançar seus propósitos. A região Sul obteve os maiores índices de concordância quanto ao desenvolvimento de estratégias pelo modo "planejado".

Nesta perspectiva mais deliberada de se criar estratégias, foi observado que $87,30 \%$ das empresas participantes da pesquisa possuem em seus objetivos a dimensão ambiental. Esta evidência traz algumas implicações para a gestão do negócio, pois sinaliza para seus empregados o compromisso da empresa com o meio ambiente; direciona a alocação de recursos e esforços para este fim; permite a criação de metas; e orienta o estabelecimento de estratégias nos níveis funcionais.

Os modos processual e guarda-chuva tiveram percentuais de respostas superiores a $50 \%$. Isto implica que o setor, além de formalizar o tipo de estratégia a ser seguida, também se preocupa com a forma como o conteúdo das estratégias será desenvolvido (processual) e dá algum grau de liberdade para que ações sejam tomadas no interior dos departamentos (guarda-chuva). O Sudeste obteve maior índice de empresas que adotam o método guarda-chuva e processual.

O modo imposto, por sua vez, apresentou também um percentual de concordância significativo, sugerindo que incertezas do ambiente externo e variabilidades internas exigem decisões incrementais, que privilegiam o aprendizado e exigem flexibilidade da organização para responder rapidamente aos eventos impostos e que não foram contemplados em planos prédefinidos.

Os modos empreendedor e não-conectados apresentaram os menores níveis de concordância entre as empresas pesquisadas. Considerando as características de cada um deles e os resultados já apresentados dos demais modos, percebe-se que o alto grau de formalidade $(75,5 \%$ das organizações possuem planos formais que estabelecem a gestão ambiental) encontrado nas empresas pesquisadas vai de encontro à informalidade normalmente presente em modelos empreendedores. Ademais, a alta participação $(87,1 \%)$ de membros de diferentes departamentos no processo de elaboração do planejamento estratégico parece contribuir para diminuir conflitos internos e comportamentos políticos disfuncionais que conduzam ao desalinhamento entre estratégias funcionais e empresariais.

Os resultados desta pesquisa podem contribuir para um melhor entendimento da dinâmica da elaboração da estratégia. Apesar de os modos de formação de estratégias, a exemplo de escolas do pensamento estratégico, serem apresentados em separado na literatura, as evidências empíricas permitem concluir que eles podem ocorrer concomitantemente, de forma combinada, no processo de criação das estratégias, sem a exigência de adesão a um único modo.

Além disso, a percepção de que a regulamentação ambiental e o acesso ao crédito sejam dois importantes fatores que motivam as empresas do setor sucroalcooleiro a investirem recursos e demandarem esforços em prol do meio ambiente podem também fortalecer os argumentos a favor da: 1- eficácia da criação e manutenção de normas e leis ambientais; 2- ampliação, por parte de instituições financeiras públicas e provadas, da adoção de critérios de risco ambiental como condicionantes para concessão de empréstimos financeiros.

A principal limitação da pesquisa foi a utilização do banco de dados disponibilizado em 2011 pelo Ministério da Agricultura, Pecuária e Abastecimento. Apesar de ser o mais "atual", foram 
encontradas diversas inconsistências de números telefônicos para contato com as usinas. No entanto, pesquisas por meio das ferramentas de busca na internet foram empreendidas, a fim de minimizar o impacto causado pela não atualização dos dados.

Quanto ao desenvolvimento de futuras pesquisas, sugere-se que os seguintes estudos sejam realizados: analisar o processo de implementação das estratégias de gestão ambiental no setor sucroalcooleiro; e identificar como ocorre o processo de geração da inovação e disseminação tecnológica no setor sucroalcooleiro.

\section{REFERÊNCIAS}

Alperstedt, G. D., Quintella, R. H. \& Souza, L. R. (2010) Estratégias de gestão ambiental e seus determinantes: uma análise institucional. Revista de Administração de Empresas - RAE, 50(2), 170-186, abr./jun.

Aragón-Correa, A., Sharma, S. (2003) A contingent resource-based view of proactive corporate environmental strategy. Academy of Management Review, 28(1), 71-88.

Araújo, R. M. S. (2001) Análise da gestão ambiental em empresas agroindustriais de usinas de açúcar e álcool no Mato Grosso do Sul. Dissertação (Mestrado em Administração) - Programa de Pós-Graduação em Administração, Universidade do Rio Grande do Sul, Porto Alegre.

Babbie, E. (2003) Métodos de pesquisa de survey. Belo Horizonte: Editora UFMG.

Barbieri, J. C. (1995) Avaliação de impacto ambiental na legislação brasileira. Revista de Administração de Empresas - ERA, 35(2), 78-85, Mar./Abr.

Barbieri, J. C. (2007) Gestão ambiental empresarial: conceitos, modelos e instrumentos. (2ed.) São Paulo: Saraiva.

Brasil, Ministério da Agricultura. (2012) Plano Agrícola e Pecuário 2010 - 2011. Brasília: Mapa/SPA, 2010. Recuperado em: 12 abril, 2014, de:

<http://www.agricultura.gov.br/arq_editor/file/MAIS\%20DESTAQUES/Plano\%20Agr\%C3\%ADco la\%20e\%20Pecu\%C3\%A1rio\%202010-2011.p>.

Borin, N., Cerf, C. D., Krishnan R. (2011) Consumer effects of environmental impact in product labeling. Journal of Consumer Marketing, 28, 76 - 86.

Burrell, G. \& Morgan, G. (1979) Sociological paradigms and organizational analysis. London UK: Heinemann.

Clarkson, P. M., Li, Y., Richardson, G. D., Vasvari, F. P. (2011) Does it really pay to be green? Determinants and consequences of proactive environmental strategies. Journal of Account and Public Policy, 30(2), 122-144.

Costa, F. J. (2011) Mensuração e desenvolvimento de escalas: aplicações em Administração. Rio de Janeiro: Editora Ciência Moderna.

Donaire, D. (2006) Gestão ambiental na empresa.(2 ${ }^{\mathrm{a}}$ ed.) São Paulo: Editora Atlas.

Egri, C. P. \& Pinfield, L. T. (1999) As organizações e a biosfera: ecologia e meio ambiente.In: 
Clegg, S., Hardy C. \& Nord, D. Handbook de estudos organizacionais. São Paulo: Atlas.

Escobar, H. (2012) Energia da cana vale 3 belo monte. Recuperado em: 6 de junho de 2014, de: < http://www.estadao.com.br/noticias/vidae,energia-da-cana-vale-3-belo-monte,603472,0.htm>.

Fao. Fundação das Nações Unidas para Agricultura e Alimentação. (2012) Production de produits alimentaires et agricoles. Recuperado em: 23 de abril de 2014, de: < http://faostat.fao.org/site/339/default.aspx>.

Greeno, J. L., Robinson, S. N. (1992) Rethinking corporate environmental management. Columbia Journal of World Business, 27, 222.

Hair, J. F., Anderson, R.E., Tatham, R.L. \& Black, W.C. (2009) Análise multivariada de dados. (6 ed.) Porto Alegre: Bookman.

Hardin, Garrett. (1968) The tragedy of the commons. Science, (162), 1243-1248.

Haynes, S. N., Richard D. C.S. \& Kubany, E. S.(1995) Content validity in psychological assessment: a functional approach to concepts and methods. Psychological Assessment, 17(3), 238247.

Hunt, C. B., Auster, E. R. (1990) Proactive environmental management: avoiding the toxic Trap. Sloan Management Review, 31(2), 7-18.

Levin, J. (1987) Estatística aplicada a ciências humanas. (2ª ed.) São Paulo: Harbra.

Machado, A. G. C. \& Silva, J. C. S. (2010) Estratégia empresarial e práticas ambientais: evidências no setor sucroalcooleiro. Revista Brasileira de Gestão de Negócios, 12(37), 405-424.

Maimon, D. (1994) Eco-estratégia nas empresas brasileiras: realidade ou discurso. Revista de Administração de Empresas - RAE, 34(4), 119-130, Jul./Ago.

Marinho, M. de.S. C. (1990) A questão dos objetivos nas organizações. Revista de Administração de Empresas - RAE, 30(2), 5-22, abr./jun.

Mintzberg, H. (1973) Strategy-making in three modes. California Management Review, 16(2), 4453, winter.

Mintzberg, H., Ahlstrand, B. \& Lampel, J. (2000) Safári de estratégia: um roteiro pela selva do planejamento estratégico. Porto Alegre: Bookman.

Mintzberg, H. \& Waters, J. A. (1985) Of strategies, deliberate and emergent. Strategic Management Journal, 6(3), 257-272.

Motta, S. L.S., Oliveira, B. (2007) O marketing ecológico como vantagem competitiva. Revista de Gestão USP, 14(2), 49-59, abril/junho.

ONU. Organização das Nações Unidas no Brasil. (2012) Retrospectivas 2011. Recuperado em: 18 de abril de 2014, de: 〈http://www.onu.org.br/onu-lanca-retrospectiva-2011/>.

Pelizer, L. H., Pontieri, M. H.\& Moraes, I. M. O. (2007) Utilização de resíduos agro-industriais em 
processos biotecnológicos como perspectiva de redução do impacto ambiental. Journal of Technology Management \& Innovation. 2(1), 118-123.

Piacente, F. J. (2005) Agroindústria canavieira e o sistema de gestão ambiental: o caso das usinas localizadas nas bacias hidrográficas dos rios Piracicaba, Capivari e Jundiaí. Dissertação (Mestrado em Desenvolvimento Econômico) - Universidade Estadual de Campinas, Campinas.

Pickett-Baker, J., Ozaki, R. (2008) Pro-environmental products: marketing influence on consumer purchase decision. The Journal of Consumer Marketing, 25(5), 281-293.

Porter, M. E.\& Linder, C. (1995) Verde e competitivo superando o impasse. Harvard Business Review, 73(5), 120-134.

Quinn, J. B. (1978) Strategic change: "logical incrementalism”. Sloan Management Review, 20(1), 7-21.

Rohrich, S. S. \& Cunha, J. C. (2004) A proposição de uma taxonomia para análise da gestão ambiental no Brasil. Revista de Administração Contemporânea, 8(4), 81-97.

Sanches, C. S. (2000) Gestão ambiental proativa. Revista de Administração de Empresas - Rae, 40(1), 76-87, Jan./Mar.

Sampieri, H. S., Collado, C. F. \& Lucio, P. B. (1991) Metodología de La investigación. México: McGraw - Hill.

Santos, L. L. S., Alves, R. \& Almeida, K. N. T. (2007) Formação de estratégia nas micro e pequenas empresas: um estudo no centro-oeste mineiro. Revista de Administração de Empresas, 47(4), Out./Dez.

Sharma, S., Vredenburg, H. (1998) Proactive corporate environmental strategy and the development of competitively valuable organizational. Strategic Management Journal, 19(8), 729-753.

Udop. União dos Produtores de Bioenergia. (2010) Subprodutos da cana se tornaram fonte de receita. Recuperado em: 28 de maio de 2014, de: <

http://www.udop.com.br/index.php?item=noticias\&cod=907>.

Unica. União da Indústria de Cana-de-Açúcar. (2014) Maior produtor mundial de cana e açúcar, 2014. Recuperado em: 20 out. 2014, de:< http://www.unica.com.br/faq/>.

Van de Ven A. H. (1992) Suggestions for studying strategy process: a research note. Strategic Management Journal, 13, 169-188.

Vasconcelos, F. (2001) Safári de estratégia, questões bizantinas e a síndrome do ornitorrinco: uma análise empírica dos impactos da diversidade teórica em estratégia empresarial sobre a prática dos processos de tomada de decisão estratégica. In: Enanpad, 25, Anais... Campinas: Anpad, set. 15 p. 
Apêndice A - Frequências das variáveis utilizadas para delimitação do perfil da amostra.

\begin{tabular}{|c|c|c|}
\hline & Variável & Frequência Absoluta \\
\hline \multirow{5}{*}{ 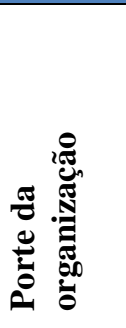 } & Microempresa - Faturamento anual menor ou igual a R\$ 2,4 milhões & 1 \\
\hline & $\begin{array}{l}\text { Pequena empresa - Faturamento anual maior que } \mathrm{R} \$ 2,4 \text { milhões e menor ou } \\
\text { igual a } \mathrm{R} \$ 16 \text { milhões }\end{array}$ & 7 \\
\hline & $\begin{array}{l}\text { Média empresa - Faturamento anual maior que R } \$ 16 \text { milhões e menor ou } \\
\text { igual a R } 90 \text { milhões }\end{array}$ & 27 \\
\hline & $\begin{array}{l}\text { Média-grande empresa - Faturamento anual maior que R\$ } 90 \text { milhões e } \\
\text { menor ou igual a } R \$ 300 \text { milhões }\end{array}$ & 37 \\
\hline & Grande empresa - Faturamento anual maior que R\$ 300 milhões & 30 \\
\hline \multirow{19}{*}{ 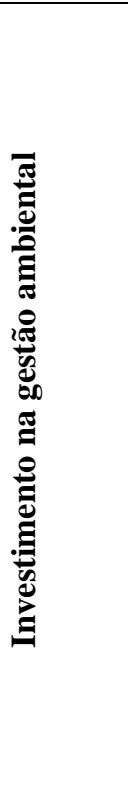 } & Microempresa - Entre $0,1 \%$ e $0,3 \%$ do faturamento & 1 \\
\hline & Pequena empresa - Entre $0,1 \%$ e $0,3 \%$ do faturamento & 4 \\
\hline & Pequena empresa - Entre $0,31 \%$ e $0,6 \%$ do faturamento & 2 \\
\hline & Pequena empresa - Entre $0,61 \%$ e $0,9 \%$ do faturamento & 1 \\
\hline & Média empresa - Entre $0,1 \%$ e $0,3 \%$ do faturamento & 8 \\
\hline & Media empresa - Entre $0,31 \%$ e $0,6 \%$ do faturamento & 11 \\
\hline & Média empresa - Entre $0,61 \%$ e $0,9 \%$ do faturamento & 2 \\
\hline & Média empresa - Entre $0,91 \%$ e $1,2 \%$ do faturamento & 2 \\
\hline & Média empresa - Acima de $1,2 \%$ do faturamento & 4 \\
\hline & Média-grande empresa - Entre $0,1 \%$ e $0,3 \%$ do faturamento & 11 \\
\hline & Média-grande empresa - Entre $0,31 \%$ e $0,6 \%$ do faturamento & 15 \\
\hline & Média-grande empresa - Entre $0,61 \%$ e $0,9 \%$ do faturamento & 4 \\
\hline & Média-grande empresa - Entre $0,91 \%$ e $1,2 \%$ do faturamento & 3 \\
\hline & Média-grande empresa - Acima de 1,2\% do faturamento & 4 \\
\hline & Grande empresa - Entre $0,1 \%$ e $0,3 \%$ do faturamento & 5 \\
\hline & Grande empresa - Entre $0,31 \%$ e $0,6 \%$ do faturamento & 7 \\
\hline & Grande empresa - Entre $0,61 \%$ e $0,9 \%$ do faturamento & 2 \\
\hline & Grande empresa - Entre $0,91 \%$ e $1,2 \%$ do faturamento & 1 \\
\hline & Grande empresa - Acima de 1,2\% do faturamento & 15 \\
\hline \multirow{5}{*}{ 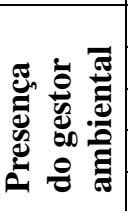 } & Investimento em gestão ambiental - Entre $0,1 \%$ e $0,3 \%$ do faturamento & 0 \\
\hline & Investimento em gestão ambiental - Entre $0,31 \%$ e $0,6 \%$ do faturamento & 3 \\
\hline & Investimento em gestão ambiental - Entre $0,61 \%$ e $0,9 \%$ do faturamento & 12 \\
\hline & Investimento em gestão ambiental - Entre $0,91 \%$ e $1,2 \%$ do faturamento & 18 \\
\hline & Investimento em gestão ambiental - Acima de $1,2 \%$ do faturamento & 21 \\
\hline \multirow{5}{*}{ 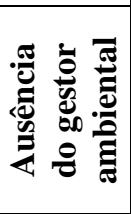 } & Investimento em gestão ambiental - Entre $0,1 \%$ e $0,3 \%$ do faturamento & 1 \\
\hline & Investimento em gestão ambiental - Entre $0,31 \%$ e $0,6 \%$ do faturamento & 6 \\
\hline & Investimento em gestão ambiental - Entre $0,61 \%$ e $0,9 \%$ do faturamento & 16 \\
\hline & Investimento em gestão ambiental - Entre $0,91 \%$ e $1,2 \%$ do faturamento & 17 \\
\hline & Investimento em gestão ambiental - Acima de $1,2 \%$ do faturamento & 8 \\
\hline \multirow{2}{*}{ 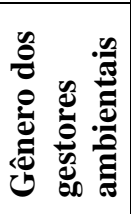 } & Mulheres & 27 \\
\hline & Homens & 74 \\
\hline \multirow{5}{*}{ 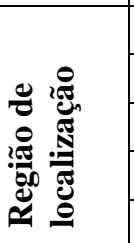 } & Nordeste & 21 \\
\hline & Norte & 1 \\
\hline & Centro-Oeste & 12 \\
\hline & Sul & 9 \\
\hline & Sudeste & 59 \\
\hline
\end{tabular}

Fonte: Dados da pesquisa (2012)

Recebido em: 20/08/2013

Publicado em: 30/08/2014

Revista de Gestão Social e Ambiental - RGSA, São Paulo, v. 8, n. 2, p. 76-93, maio/ago., 2014. 